\title{
Blues: um ensaio etnográfico sobre cultura e reflexos na indumentária
}

\author{
Blues: an ethnographic essay about culture and its reflections on \\ clothing
}

PINHEIRO, Cristiano Max Pereira

Universidade Feevale I maxrs@feevale.br

SILVA, André Conti

Universidade Feevale I andrec@feevale.br

PETRY, Morgana Schoerpf

Universidade Feevale

WISSMANN, Débora

Universidade Feevale I debora.w@feevale.br

\begin{abstract}
Resumo
O presente artigo tem como intento discorrer acerca das relações histórico-socioculturais que mediaram e determinaram o texto visual na cultura do blues, objetivando desenvolver uma coleção de alfaiataria. Pressupõe-se que a moda, como um veículo simbólico, esteja de maneira intrínseca ligada com o pensar do indivíduo e suas manifestações, por intermédio de seus textos visuais. Assimilar esses sinais de comunicação de personalidade exteriorizados por meio da moda, sob o viés dos fenômenos culturais é

\section{Abstract}

This paper aims at discussing the socio-culturalhistorical relations that brokered and determined the visual narrative in the blues culture, in order to develop a collection of tailored clothing. It is assumed that fashion, as a carrier of symbolic meaning, is intrinsically linked to the individual thinking and its manifestations through the visual narrative. This analysis is guided by the associations between the communication signals of personality under the perspective of cultural phenomena.
\end{abstract} o norte da análise.

Palavras Chave: Blues. Identidade cultural. Indumentária. Movimento de estilo Zoot-Suit.

Keywords: Blues. Cultural identity. Clothing. Zoot-Suit style movement. 


\section{INTRODUC̣ÃO}

O passado influenciou muito a formação do mundo de hoje. Retomar alguns pontos da sua história auxilia-nos a compreendermos as transformações pelas quais passaram as sociedades humanas em seu tempo e espaço, a dimensão que o homem teve e tem. Os caminhos percorridos e os acontecimentos fornecem relevantes explicações de nossas origens, processos de aquisição de valores culturais, sociais e tecnológicos. A capacidade de deslocar-se por esses caminhos revela o amplo papel que um povo carrega para afirmar-se. A indumentária, inserida no próprio desenvolvimento da humanidade e, consequentemente, no progresso e mudanças de costumes, expressa valores, usos e hábitos. Elemento ativo na elaboração e reelaboração das práticas culturais tradicionais e influenciadora de outras novas.

Muitos indivíduos encontram na música formas de revelação de suas culturas. Ela possui variáveis apropriações, usos e sentidos dentro da sociedade na qual está inserida (e se insere). A cultura exerce um papel fundamental para delimitar as variadas personalidades, os padrões de conduta e as características próprias de cada grupo humano. A identidade, única e distinta, completa, tanto na percepção individual ou coletiva, pode ser vista como um trânsito intenso e complexo. Produzindo o sentido de saber se reconhecer, a identidade cultural compõe um conjunto de relações sociais e patrimônios simbólicos historicamente compartilhados, que estabelece a comunhão de determinados valores entre os membros de uma sociedade (HALL, 2002).

Gênero musical popular, o blues desafiou durante muito tempo os hábitos da escrita musical, pois descende de uma longa tradição oral (MUGGIATI, 1995). Seu estudo profundo, ao contrário de muitos outros ritmos, apoia-se em raras fontes escritas, na escuta atenta e comparativa das gravações sonoras. A sua história, evolução e sucessivas mutações são inseparáveis da longa luta pela inclusão na sociedade de direitos e formação do povo afroamericano; para quem, durante décadas, mais do que música, o blues significou seu principal meio de expressão (POSTALI, 2011). Apenas um século separa o fim da Guerra Civil e a emancipação dos escravos negros do reconhecimento internacional do blues. A dimensão e o prestígio que ele alcançou, por sua originalidade, vigor e riqueza, leva a sua música a ser permanentemente revisitada. Na tentativa de compreender os complexos mecanismos que determinaram certa "adoção de aparência" no blues, este artigo terá como propósito traçar os aspectos essenciais das relações socioculturais que mediaram a criação e as transformações no uso da vestimenta do bluesman - cantor de blues ou "bluseiro".

A moda e seu estudo desde as origens e sua consequente evolução, como fenômeno cultural, demonstra como sua função de indicar status social foi gradativamente alterada para a de fator de construção da identidade do indivíduo, mediante sua correspondência com valores que cada um escolhe 
cultivar. A linguagem simbólica das roupas e a maneira como informam sobre a orientação sociopolítica servem como fontes de informação sobre costumes e hábitos de um povo. Estes serão os elementos usados para delinear as mudanças na natureza das relações entre as classes sociais e estilos de vida, alargar a compreensão da cultura material e de seus códigos. Interessante realçar que esses estudos são subdesenvolvidos, pois, embora as narrativas de vestuário elegante deem a impressão de consenso, a moda na verdade envolve um alto grau de debate e controvérsia (CRANE, 2006).

O vestuário e os estilos, relacionados em si, são carregados de uma ampla gama de significados ideológicos, verdadeiras "pautas sociais". Os estilos assimilam o real de uma maneira diferente e complementar à linguagem. As aparências não enganam: sempre houve indivíduos ou grupos que exprimiram sua revolta contra as normas sociais por meio da vestimenta. Segundo Bollon (1993), os movimentos de estilo correspondem a um tipo de música, mentalidade e estética, sistemas inteiros de significação: suas manifestações desafiam normas de bom gosto vigentes e revelam uma relação histórica e política. Do próprio processo de criar cultura e de sua intrínseca necessidade para sobrevivência e progresso, emergiram, espontaneamente, movimentos como o denominado zoot-suit. O estilo representativo surgiu em meio a subculturas afro-hispano-americanas do Harlem e de Los Angeles, e teve o seu apogeu durante a 2a Guerra Mundial (BOLLON, 1993). Neste trabalho, esse discurso, expresso por meio da reivindicação à dignidade diante da desumanização e da discriminação, fundamenta a relação com a aparência do bluesman e a formação cultural desta.

\section{O BLUES E O VESTUÁRIO}

O blues é um gênero musical popular vocal e ou instrumental, com fortes raízes estilísticas na África Ocidental. Ligado em alto grau à cultura afroamericana oriunda do Sul dos EUA (Alabama, Mississipi, Louisiana e Georgia predominantemente), misturou ritmos e melodias africanas e europeias (MUGGIATI, 1995).

Em 1900, dos 10 milhões de negros em solo americano, 90\% moravam em estados sulistas. Grande parte trabalhava nas terras das regiões algodoeiras, que mantinham os negros formalmente livres, porém, cativos economicamente. As relações trabalhistas eram constituídas, em sua maioria, pelo sistema chamado sharecropping (meeiros), uma espécie de arrendamento das terras de latifundiários brancos (TOTA, 2009).

Neste contexto, o blues originou-se, basicamente, do canto dos escravos nas plantações de algodão, as chamadas work-songs (canções de trabalho). Há quem defenda que o blues também nasceu a partir das chamadas spirituals, 
canções criadas pelos escravos a partir das histórias da Bíblia e da música religiosa. Uma consequência de os negros sofrerem evangelização maciça no início do século XIX, contexto no qual o canto religioso africano era proibido (MUGGIATI, 1995).

De acordo com o intelectual James Weldon Johnson Roberts, autor do livro Autobiografia de um Ex-negro (ROBERTS, 2010), as jubilee songs ou spirituals eram canções entoadas pelos escravos negros como uma forma de expressar sua religiosidade e suportar as agruras do trabalho durante o cativeiro; não raro, carregavam também planos de revolta e fuga. Outro fator seria a leitura da Bíblia, que possibilitou aos escravos o aprendizado das primeiras letras, em uma época na qual a educação dos negros era proibida. Contudo, Muggiati (1995) assegura que o blues tem muito mais a ver com a realidade prática das work-songs (os cantos ressoados nas rotinas opressivas de trabalho e de vida) mas que, musicalmente, os hinos religiosos também deram sua contribuição: para ele, os acordes básicos do blues provêm da harmonia europeia.

Até o momento, com um vasto campo de interpretações dos inúmeros pesquisadores, a palavra "blues" ainda é um mistério e as suas origens continuam obscuras. O termo "definia um estado de espírito e já no século XVI existia a expressão blue-devils, demônios da tristeza"; já os primeiros registros escritos datam do século XIX, com um sentido de tristeza profunda ou depressão (RIBEIRO, 2000, p. 12). Um consenso entre os estudiosos do gênero é que o blues só se tornou conhecido quando a sua essência passou a ser um meio de descrever o estado de espírito da população afroamericana, após o término da Guerra Civil.

Nos anos 1920, o blues ingressava na era da comunicação de massa. Seu primeiro registro fonográfico, a gravação de Crazy Blues por Mamie Smith (18831946), inaugurava todo um novo período (o das divas) e o fixava como Classic Female Blues (MUGGIATI, 1995). Outro fator responsável pela consolidação do blues foi o início de uma revolução tecnológica, em cidades como Chicago e New York. Com a nova tecnologia da reprodução sonora, surgia a "era do gramofone", inaugurando o mercado de discos. Na época, o método mecânico passaria para o método elétrico, aperfeiçoando as gravações e estimulando ainda mais o consumo destas obras. (MUGGIATI, 1995). Junto, havia mais um fator: o potencial para as race records, gravadoras de discos destinados à população negra. Os discos continham uma faixa de cada lado e custavam em torno de 75 centavos, possibilitando a venda nos bairros negros das grandes cidades e pelo correio para os consumidores das zonas rurais (HERZHAFT, 1989).

Os primeiros palcos dos bluesmen foram as humildes jook joints: barracos de madeiras que abrigavam uma mistura de bar, salão de dança e sala de concerto. Segundo Muggiati (1995), praticamente todas as cidades 
do Delta possuíam uma ou duas dessas. Situadas o mais longe possível das igrejas, representavam a contrapartida da missa de domingo: eram os embalos de sábado à noite. Antes de as jukeboxes (máquinas nas quais se coloca uma moeda para um disco tocar a escolha do cliente) substituírem os cantores, estas festas eram animadas pelas doses de bebidas clandestinas da Lei Seca (os proprietários pagavam aos policiais para manterem o olho fechado), servidas em copos de lata ou canecas de vidro (verdadeiras armas para qualquer confusão que acontecesse, o que era comum), ao som dos blues.

Em uma época na qual um disco não ultrapassava três minutos de música, os blues das jooks chegavam a durar meia hora ou mais e as cenas de duelos musicais eram comuns. Normalmente os bluesman eram desafiados por um e outro cantor. Segundo o autor, especialistas em blues apontam algumas gravações de Eddie James House (mais conhecido como Son House, um influente cantor e guitarrista de blues) como notáveis reconstituições das músicas que se fazia nas jook joints. Outro grande cantor e guitarrista do Delta foi Tommy Johnson (1896-1956), conhecido por seu falsete vocal e modo de tocar.

A importância dessas profusões musicais foi sentida pelos pequenos produtores independentes que, na mesma proporção, criaram marcas registradas, dentre as quais algumas se tornaram grandes companhias. O conjunto das prolíficas produções discográficas detinha um apreciável nível artístico, o testemunho de uma incomparável riqueza musical. Por muito tempo, o único lugar onde existiam estúdios de gravação de boa qualidade técnica, junto da região de New York, era Chicago. Assim, muitos artistas foram ao seu encontro para gravar, o que explica, em certa medida, a sua solidez na tradição do blues (HERZHAFT, 1989).

Na segunda metade do século $X X$, a experiência de guerra ampliou o desejo por mais igualdade e liberdade, por meio de vozes alternativas contestando a conformidade social e cultural, a falta de direitos civis e os limites da afluência econômica (KARNAL et al., 2011). A participação maciça dos negros também desempenhou um papel determinante na afirmação de uma nova atitude afro-americana nos EUA (TOTA, 2009). Essa fase da história viria a ser marcada como o revival do blues, a autenticação do blues elétrico: a eletrificação, associada com o rock ' $n$ ' roll comercializado, apareceu como uma diluição moderna da pureza dos "velhos tempos" (HERZHAFT, 1989).

Em seus tempos de "ruptura periódica", o blues já havia pisado em solo britânico e, por meio das ondas sonoras do rádio, era cortejado por muitos jovens brancos "da geração": Rolling Stones, Johnny Winter, Duane \& Greg Allman, George Thorogood, Ry Cooder, John P. Hammond, Stevie Ray Vaughan, entre outros. Em 1958, Waters foi um dos primeiros bluesmen a invadir a praia britânica (MUGGIATI, 1995). 
Produto artístico derivado da segregação nos EUA e cuja origem está ligada a um passado de preconceito quanto a raça e gênero, o blues foi capaz de superar estas condições e alcançar o mainstream branco. Assim, aquilo que inicialmente foi considerado música negra, tornou-se um novo produto cultural, no qual os traços de "negritude" são cada vez mais difíceis de localizar. A longo prazo, o aumento do "branqueamento" do blues não leva a uma forma mais flexível, mas sim a uma conceituação mais rígida: situar o seu desempenho em seu contexto histórico, que é parte do renascimento popular, conduz a debates acadêmicos e sobre autenticidade, os quais beiram a sombra da discriminação racial (MUGGIATI, 1995).

Graças ao reconhecimento local, nacional e internacional de seu valor, hoje o blues se constitui em palco importante, permitindo a inúmeros artistas uma carreira musical. Na encruzilhada do futuro, tocar blues e discorrer sobre suas possíveis correlações é participar da sociedade em movimento, compreender a fértil história do século XIX e XX, e projetar novos capítulos para o século XXI.

O vestuário, "sendo uma das mais evidentes marcas de status e de gênero - útil, portanto, para manter ou subverter fronteiras simbólicas", compõe indicações de como as pessoas, em dessemelhantes épocas, veem sua posição nas estruturas sociais e negociam fronteiras de status (CRANE, 2006, p. 21). Em sociedades de classes, cada classe possui uma cultura distinta que a distingue das outras e na qual, ao mesmo tempo, partilha certos valores, objetivos e ideias de gênero - nessas, a cultura dominante e prestigiosa é aquela da classe alta; "as elites possuem o poder de estabelecer os termos através dos quais se conferem valor moral e social aos gostos" (CRANE, 2006, p. 32).

Ao longo do século XIX, consistiu em um padrão preciso de apresentação largamente adotado, ao menos nas cidades - tanto nos EUA quanto na Inglaterra e na França: os homens de todas as classes sociais adquiriram modelos semelhantes de vestimentas, basicamente casacos e calças. Enquanto, de modo geral, o novo era gradualmente aceito, formas tradicionais, particularmente na classe operária, continuavam a ser usadas, tais como a calça.

No final do século XIX, o vestuário havia gradualmente diminuído de custo e se tornado mais acessível às camadas baixas da população. Como primeiro item de consumo disponível em larga escala, as roupas tiveram uma significação a mais e, por vezes, representavam um luxo tanto para ricos quanto para pobres: "o vestuário era útil para "confundir" o ranking social, como meio de desvencilhar-se de restrições sociais e aparentar mais recursos sociais ou econômicos do que na verdade se tinha". Concomitantemente, como meio de indicar status, "no sentido de afirmar o verdadeiramente adquirido ou reforçar a afiliação a grupos sociais específicos que se vestiam de modo característico" (CRANE, 2006, p. 135). 
O terno de trabalho começa a ser visto mais como um uniforme que esconde a identidade do indivíduo do que um traje que a revela. Uma das características que distinguem um uniforme é que ele oculta a individualidade. A gravata, conservadora ou chamativa, serve como indicação do nível de comprometimento de quem a usa com a mensagem transmitida pelo terno (CRANE, 2006).

Movimento que pode ser considerado de contracultura à época, pois seus ideais e estilo de vida fugiam completamente aos padrões e confrontavam a sociedade convencional, o zoot-suit (ou zoot-suiters) está vinculado a subculturas étnicas que viviam em zonas urbanas do Norte dos EUA, especialmente afroamericanas e hispânicas (mexicanos). Associado às décadas de 1930-50, emergiu espontaneamente no meio musical dos principais clubes de jazz de New York: "entre a clientela mista do Onyx e do Famous Door, na rua 52, Swing Street, de Manhattan, ou ainda no lendário Savoy Ballroom do Harlem, o lugar de exibição dos dândis e posudos negros da Grande Maçã" (BOLLON, 1993, p. 77).

Estilo exclusivamente masculino, o terno zoot-suit era constituído basicamente de paletó na altura dos joelhos, realçado com ombreiras que davam à silhueta um aspecto geométrico. Normalmente, um, dois ou até três números acima do tamanho normal (CRANE, 2006). A calça era afunilada: começava larga na altura da cintura e terminava justa na bainha. Por fim, sobre o todo pousava um chapéu de abas largas. O traje dava um aspecto de gângster da sociedade. No entanto, "ficaria incompleto se esquecêssemos de pontuá-lo com um lenço de bolso de cor berrante, vermelho-papoula ou verde-maçã, e com uma enorme flor na lapela; e também nele pendurar a imensa corrente de relógio" (BOLLON, 1993, p. 78).

Conforme Bollon (1993), a palavra-chave era exagero e, em todas as dimensões possíveis, o paletó flutuava, encompridava-se por todos os lados, como que "maximizado". Os seus acessórios, como chapéu, sapato, gravata e corrente de relógio, eram especialmente notáveis porque excediam, de uma maneira ou outra, as proporções consideradas "normais", ditadas pela elegância - os ternos zoot-suit eram grandes ou pequenos demais, nunca no meio-termo da "harmonia". Quanto aos detalhes, era como se fosse preciso usar todos os recursos da arte dos alfaiates - a exemplo de pregas, lapelas, pinças, virolas e martingales. As cores pareciam não ter outra finalidade, se não a de tornaremse mais vistosas.

Oszoot-suiters eram narradores de uma história contraditória e complexa, desfilando o modo de ser do submundo das cidades urbanas. Representavam os "mordomos de algo desconfortável", um lembrete espetacular de que a "ordem social" não conseguiu conter a sua energia e diferença. Na forma direta e óbvia, tornou-se o emblema das etnias e uma maneira de negociar uma identidade: era a recusa, o gesto subcultural que se nega a admitir os modos de servilismo. 


\section{MÉTODO}

A questão consiste em desenvolver uma coleção de alfaiataria, com base cultural e histórica nos aspectos que permeiam o cultivo do blues, para a Gift Shop do Mississippi Delta Blues Bar, cujo público-alvo são músicos. O estabelecimento se localiza em Caxias do Sul, na região da Serra Gaúcha, uma cidade de vanguarda no cenário blues no Estado do Rio Grande do Sul.

Para tais procedimentos, utilizaremos os métodos de natureza aplicada, exploratória e explicativa, pois a meta é compreender a cultura blues e aprofundar o conhecimento sobre a vestimenta do cantor. A metodologia de trabalho é, inicialmente, composta por técnicas de investigações bibliográficas (levantamentos históricos), audiovisuais, fotográficas e virtuais. A seguir, apresenta um ensaio etnográfico que visa o estudo dos objetos e suas relações, "ao longo do tempo com o envolvimento e a inclusão do observador no processo. Pressupõe o contato direto com o dado, as pessoas, o fenômeno etc." (PRODANOV; FREITAS, 2013, p. 40). A pesquisa qualitativa de campo teve o foco de gerar as informações necessárias para a conceituação do Mississippi Delta Blues Bar e sua Gift Shop; e, simultaneamente, a aparência do músico de blues na atualidade e o mapeamento das próximas etapas do processo criativo. A coleta das informações, dados e evidências foi realizada por meio da observação participante e outras técnicas, como entrevistas não e semiestruturadas, além das análises, sistematizadas em doze vivências cronológicas, desde maio de 2012 até agosto de 2013.

Até o momento, analisamos de forma sistêmica a cultura do blues - seu cenário histórico e contexto sociocultural -, tentando identificar os aspectos essenciais das relações que mediaram a criação e as transformações na indumentária do bluesman - seus elementos e possíveis códigos e significações. O campo de ação desta pesquisa procura simultaneamente identificar os traços que conceituam a Gift Shop do Mississippi Delta Blues Bar e o próprio estabelecimento, além da aparência do músico de blues na atualidade. Para tal abordagem qualitativa, a metodologia aplicada foi a de um ensaio etnográfico, ou seja, a inserção do pesquisador no ambiente investigado (GIL, 2008). Esta técnica possibilitou ao mesmo tempo o mapeamento das próximas etapas do processo criativo no desenvolvimento da coleção de alfaiataria.

Amparado nessa lógica, de acordo com os recursos financeiros da pesquisadora e acesso a lugares e eventos, o ensaio ocorreu gradualmente, em grande medida nos ambientes de trabalho dos músicos: bares noturnos do circuito gaúcho. Estas incursões resultaram na sistematização de doze vivências cronológicas, registradas a partir de maio de 2012 até agosto de 2013.

As vivências foram realizadas em diferentes locais, sendo que as primeiras foram realizadas no Encontro Internacional de Harmônicas Blues. No 
dia 12 de maio de 2012, que mostrou alguns elementos de destaque no vestuário da banda como sapatos bicolores, camisas de materiais brilhosos, com recortes geométricos e naipes de baralhos de cartas; no dia 15 de maio de 2012, a Opus Promoções (produtora gaúcha), promoveu um show que apresentou um estilo mais urbano de Chicago, com a mistura de roupa social com esportiva, tendo a utilização de boina, camisa com recortes geométricos e tênis.

Na vivência 03, a 7a edição do Mississippi in Concert, no dia 21 de junho de 2012, o Mississippi Delta Blues Bar realizou o 7ํ Mississippi in Concert Edição Divas - no Teatro Pedro Parenti, na Casa da Cultura, em Caxias do Sul. Durante o espetáculo, o que mais atiçou a nossa percepção foi a etiqueta presa exteriormente no punho do paletó do traje de Igor Prado. Também observamos o tecido e o conjunto, cujo efeito em palco nos remeteu à primeira vivência. No 6을 Aniversário do Mississippi Delta Blues Bar, no dia 26 de julho de 2012, nossa atenção, naquela ocasião, centrou-se na estrela principal do evento. Sua composição de vestuário mereceu destaque: a estampa do paletó, a gravata e a meia.

A quinta vivência foi no Santander Cultural Porto Alegre, no dia 02 de setembro de 2012, o estilo esportivo de chapéu, camisa pólo e calça social despertou a atenção. No dia 23 de outubro de 2012, o bar Abbey Road recebeu o cantor Ivan Márcio que contou que compra suas roupas em brechós. A sétima vivência foi a 5a edição do Mississippi Delta Blues Festival. Nos dias 22, 23 e 24 de novembro de 2012 , onde foram vistos os mesmos elementos anteriormente destacados, porém com a introdução do macacão. A visita ao Mississippi Delta Blues Bar foi a oitava vivência e aconteceu no dia 19 de dezembro de 2012. Serviu para a verificação de como funciona a loja onde se comercializam vestuários focados em grupos que apreciam o blues. Pode-se verificar a grande aparição de camisas estampadas.

Na vivência 9, fomos novamente ao Abbey Road, onde a camisa estampada continuou chamando a atenção. O Pub's Bar recebeu no dia 04 de maio de 2013, a banda Ale Ravanello Blues Combo, que teve seus integrantes trajando estilo clássico com mistura de social e esportivo. A vivência 11 foi na Confraria do Blues no Sgt. Peppers Pub Bar Restaurant and Live Music, no dia 16 de maio de 2013. Nessa apresentação o que se realçou foi a composição de chapéu preto de aba larga, bota de couro de crocodilo e cinto com fivela de metal. A última vivência foi também no Abbey Road, no dia 06 de agosto de 2013, onde o artista Taylor Jr vestia camisa esportiva e calça jeans.

Notando similaridades e diferenças, em particular como o terno tem sido adotado e adaptado pelos músicos, podemos concluir que as opções do produto ofertadas no mercado são restritas e pouco variadas. É possível explorar mais as criações - modelagem, cor, estampa e detalhes -, adaptandoas ao meio musical. 


\section{RESULTADOS}

O blues, objeto de estudo que motivou a seleção de novas informações, estabelece a linha de pensamento geradora do conceito: conforme um de seus criadores, Willie Dixon, "todo mundo leva o blues dentro de si, sem dúvida. Todo mundo leva. Mas o blues de um é diferente do de outro [...] E ninguém o expressa identicamente. Cada um o expressa de acordo com sua criação e o meio em que viveu" (THE BLUES, 2003, 1:14:00-1:14:45). Também, traz o suporte criativo para o projeto: a inspiração encontra-se amparada pelas vivências e por referências históricas.

A temática da coleção intitula-se "expressão de si, emoções e crenças eram o propósito da canção de trabalho". Ela será criada a partir das emoções e sensações despertadas nos autores (durante a pesquisa), das padronagens típicas da indumentária africana e de algumas técnicas manuais. Busca passar serenidade, por intermédio dos sentimentos musicais, àqueles que vibram até um ponto e depois trazem a calma no peito.

Consideração básica durante o processo de criação, a cor é fundamental para a assimilação de uma coleção de moda, pois é o que percebemos primeiro (UDALE, 2009). Várias razões motivam a sua escolha. Na ocasião, elas também estão estabelecidas no "Mapa Blues" (figura 1). A figura 1 as apresenta:

Figura 1 - Paleta de cores.

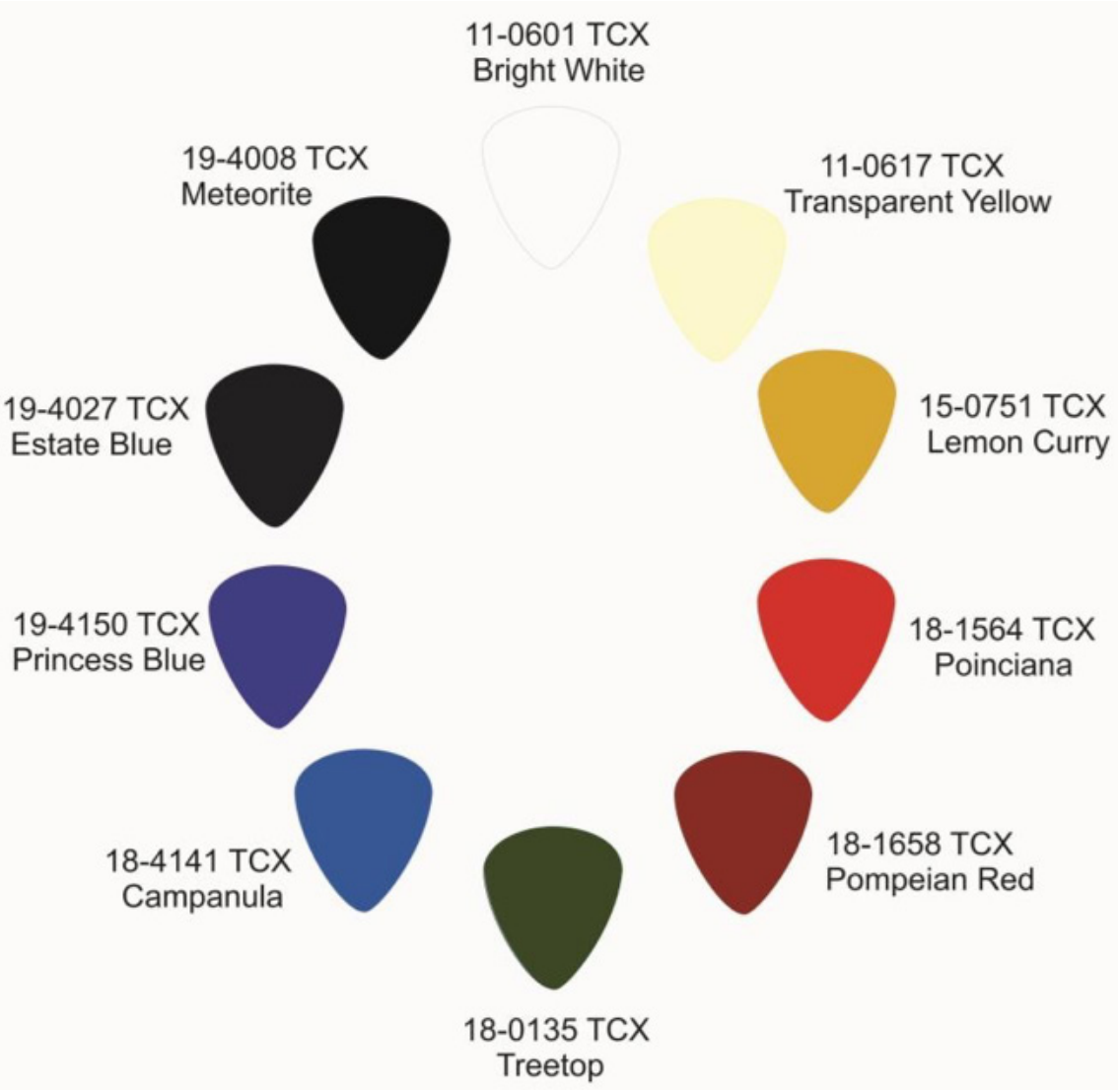

Fonte: Elaborado pelos autores, 2014. 
Em virtude da diversidade ofertada e opções variadas, a cartela propõe similaridades em uma composição contrastante, mas harmônica. Foi identificada a partir do Sistema Pantone, usando o software Kaledo (Lectra), específico do meio da Moda e Design.

Considerando a pretensão mencionada no briefing, adaptamos o tecido ao artigo que se pretende produzir. É por meio dos tecidos que o designer converte suas ideias em uma peça de vestuário (TREPTOW, 2013). Escolhemos mesclar simplicidade com rigidez e estrutura, fluidez e delicadeza. A seleção por tecidos planos e sobras de malha circular levam em conta questões de estrutura, caimento e custos. O diferencial encontra-se no tecido (Etamine) específico do artesanato Ponto Cruz (bordado), ajustado ao vestuário; e nas estampas africanas - vindos diretamente da África, esses tecidos foram obtidos por meio de doações para a coleção. Eles também serviram para delimitar a linha de base na seleção das cores.

Na composição de um modelo, pode-se prever as aplicações de estampas ou bordados (TREPTOW, 2013). O processo de criação das superfícies segue a mesma coerência dos conceitos expostos no roteiro de ação. A seleção dos desenhos para bordar ocorreu por meio de pesquisas em revistas da área Ponto Cruz e acervo pessoal da artesã terceirizada (Maria Schoerpf Petry, Santa Cruz do Sul/RS). Para as camisetas, as estampas foram desenvolvidas pela artista Marina Vieira Prudencio.

Os croquis, que são a arte-final dos desenhos, foram elaborados por meio de um raciocínio mais técnico em relação ao aspecto/peça. Esta prática viabiliza o planejamento de sua construção e a habilidade para imaginar o efeito na estrutura, auxiliando o desenvolvimento da modelagem e os possíveis recortes, os quais dão margem ao reaproveitamento de matéria-prima. Posteriormente, sofreram modificações e acréscimos, sendo vetorizados no software CoreIDRAW. A figura 2 apresenta o resultado da composição dos dez looks:

Figura 2 - Croquis.

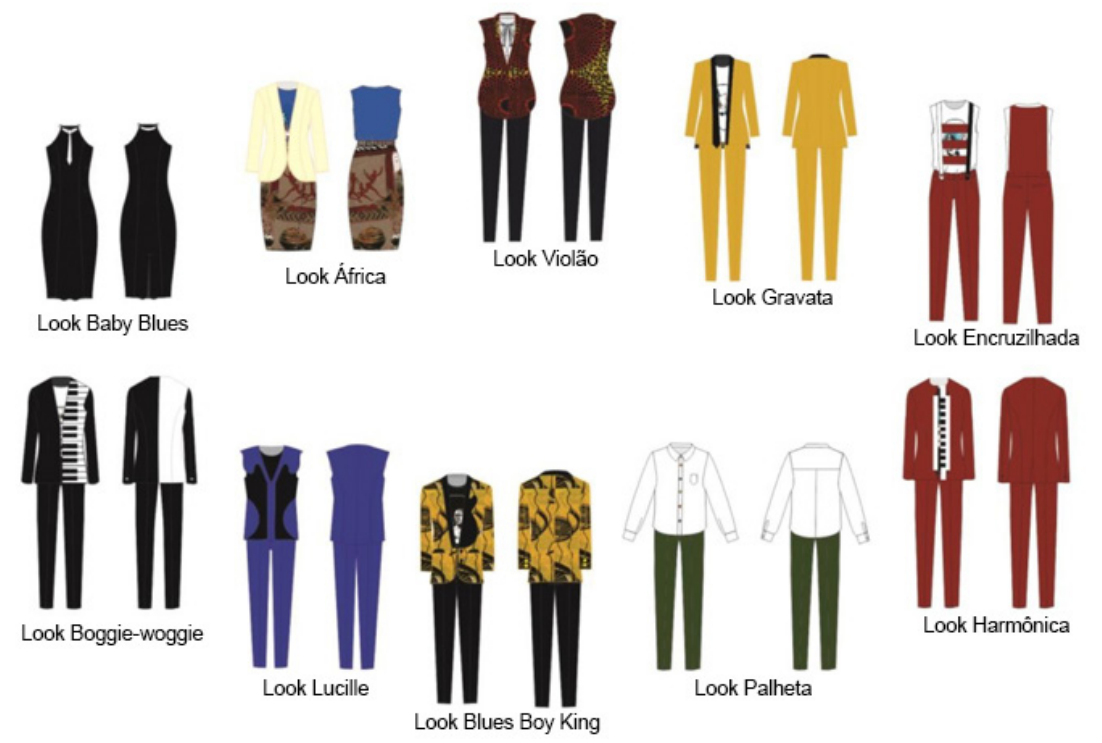

Fonte: Elaborado pelos autores, 2014.

Projética, Londrina, v.10, n.1 p. 25-40, jan./jun. 2019 
Com sentido simplificado no seu desenvolvimento, a criação da linha atemporal de vestuário "Mojo Hand" referência um estilo popular. Reúne um cenário urbano/rural e nutre o tema reciclando e racionando materiais. Incorpora medidas governamentais, aplicando algumas normas precisas do conselho de produção, encarregado de coordenar as indústrias civis durante a 2a Guerra mundial (vistas na seção Movimento de Estilo Zoot-Suit). Em contraponto ao tradicional, refina seus detalhes, deixando as versões "vigorosas". Trabalhamos os gêneros de forma a tornar onipresentes ambos os estados, buscando a atmosfera energética de sua manifestação. A priori, segue a caracterização de cada um dos looks.

O vestido Baby Blues, criado a partir da "mão da guitarra" e do vocal (boca), possibilita à gravata ser opcional e substituída a gosto: por ela mesma e/ou outros acessórios, a exemplo de colares, lenços e etc. A fim de acentuar e direcionar o olhar sutilmente para as curvas femininas, botões palheta, da mesma cor do tecido, são aplicados nas laterais.

O blazer do look África não tem forro, nem lapela, ombreira e botões, além de trazer a manga mais curta do que o habitual. Agrega valor por meio da técnica de bordar à mão, onde requer cálculos métricos. A simulação de como devem ficar localizados os desenhos na estrutura da peça não se encontram na sua representação, devido ao minucioso processo artesanal que isto implica. A saia reúne simplicidade e elegância, em tecido africano e cós detalhado com palheta preta.

A camisa branca do look Violão tem inspiração na cena do filme Crossroads (no Brasil, A Encruzilhada) quando o personagem "Willie Brown" troca a gravata tradicional que estava usando por uma gravata-laço - "[...] Você está no Mississippi, perto dos blues e da estrada. [...] esta é uma gravata cordão do Mississippi. É isso que um tocador de blues usa neste Estado. As outras são para o pessoal da cidade" (CROSSROADS, 1986, 0:30:35-0:31:40). E o colete, em uma "pegada rock ' $n$ ' roll", de padronagem africana, acompanha o trajeto, nas formas do violão (laterais costuradas até a cintura).

O paletó amarelo (look Gravata) oferta a ideia de dar nova função a acessórios presentes no guarda-roupa. No caso aqui, a gravata ajustada como gola/lapela. Também se cogita a viabilidade de usar somente gravatas (reutilizálas), em vez de tecido, para a sua construção.

O macacão do look Encruzilhada tem a parte superior funcional: pode-se retirar e usar apenas como calça. Feito com sobras de tecidos da coleção, reúne uma alusão à ferrovia e ao suspensório. É feito de tricoline liso (tecido) para dar aspecto de uniformização. 
O paletó gaita do look Harmônica consiste no ato de representar formas geométricas dos instrumentos musicais, por meio da análise de recortes na modelagem.

A camisa social do look Palheta apenas substitui aviamentos comuns (botões), por ferramentas do meio musical (palhetas). O bolso tem a intenção de simbolizar uma "insígnia de condecoração". A possibilidade de explorar materiais como lenços de bolso e gravatas no seu feitio (um aspecto mosaico) faz linha de sugestão.

O paletó estampado, do look Blues Boy King, foi inspirado nos trajes do bluesman B.B. King e refinado na lapela. A variante vai ao encontro ao clássico Smoking.

O colete azul, na "pegada rock ' $n$ ' roll", do look Lucille, faz dialogar a intensidade do artista com o instrumento musical, representando-a em seu abraço.

O paletó piano, do look Boggie-woggie segue a mesma congruência do look "Harmônica". Só que, desta vez, representa a figura por meio da técnica de aplicar os recortes na estrutura da peça. Questiona a "virilidade" trazendo a desconstrução da rigidez na alfaiataria, para exteriorizar uma/a sensibilidade do homem.

As camisetas, com base na questão de convergência entre as formas de criação, trazem uma inspiração mais rock'n'roll. A possibilidade de agregar aviamentos também foi examinada.

Na montagem das peças, o processo foi dividido e destinado à própria prática da aluna e à costura terceirizada (Teresa Limberger, Santa Cruz do Sul/ RS). Todas as peças que foram entregues à profissional estavam cortadas e acompanhadas de sua ficha-técnica. Para as camisetas, selecionamos sobras de malha na mesma cor da peça pronta. Os pedaços foram estampados (sublimação) e cortados no formato proposto, depois aplicados na estrutura. Outras modificações estão nas mangas, colarinhos e/ou acabamentos. Elas não possuem ficha técnica, pois vão ao encontro ao que é proposto: customização. Todas as peças confeccionadas trazem o selo identificador que foi manualmente produzido.

\section{CONSIDERAC̣̃̃ES FINAIS}

Por meio da aculturação ocorrida nos EUA durante seu processo de colonização, em um contexto de violência e dominação, o estado de escravidão colocou diferentes povos em situações de contato radicalmente novas. O contato 
"extremo" (a despeito do cotidiano brutal e desigual em que se encontravam) gerou processos de miscigenação e criações culturais - as certas peculiaridades culturais existentes fundiram-se, originando vários estilos e um repertório de novas formas de expressão.

Qualquer trabalho de pesquisa que vise compreender o blues, de modo inevitável encontrará o cenário musical oriundo do Delta do Mississippi em seu percurso - o legado do Delta Blues. Boa parte dos músicos contemporâneos (a exemplo de rock ' $n$ ' roll, country e R\&B) podem traçar suas influências, passo a passo, com um retorno aos rurais do século XX: especialmente aqueles do Mississippi, Louisiana e Texas. As diversas referências musicais, que os inspiram até hoje, são prova de como o blues permanece vivo em nossa sociedade.

Enfatizamos que o ensaio etnográfico foi a metodologia escolhida, por possibilitar maior abrangência, espontaneidade e veracidade aos resultados. Com este método é possível captar a intensidade do artista em relação ao seu trabalho, o elo com sua filosofia de vida: o meio artístico precisa ser livre de restrições e conceitos pré-estabelecidos, para que possa haver a transmissão de maneira fiel de suas criações. Dessa forma, as técnicas vêm ao encontro do que foi buscado junto aos músicos citados nas vivências: a forma espontânea de suas expressões e opiniões.

Observando as inúmeras manifestações, variedades e complexidades, onde, no momento, as coisas não ocorreram em sequência, mas concomitantemente, neste modelo, voltado aos grupos e comunidades locais, se buscou estabelecer caminhos para um crescimento qualitativo e de redefinição de alguns processos do sistema de valores vigente na atual economia global. Aventurando-se em um labirinto de sons, sinais e imagens, descobrimos outras maneiras de sentir o corpo na cultura. Ao encontrar uma realidade diferente por trás da aparência mecanicista superficial da vida cotidiana, a criação indagou acerca da natureza essencial das coisas. As técnicas usadas na coleção adequaram os seus métodos, a partir da desconstrução dos processos, através da história e das vivências e necessidades reais, de modo a atender a bagagem pessoal e de autoconhecimento, gerando um cenário autêntico, e deixando o caminho livre às próprias conclusões do leitor e à estudos futuros. 


\section{REFERÊNCIAS}

BOLLON, Patrice. A moral da máscara: merveilleux, zazous, dândis, punks, etc. Rio de Janeiro, RJ: Rocco, 1993.

CRANE, Diana. A moda e seu papel social: classe, gênero e identidade das roupas. São Paulo, SP: SENAC São Paulo, 2006.

CROSSROADS. Direção: Walter Hill. Escritor: John Fusco. [S. I.]: Columbia Pictures, 1986. (99 min).

GIL, Antônio Carlos. Métodos e técnicas de pesquisa social. 6. ed. São Paulo, SP: Atlas, 2008.

HALL, Stuart. A identidade cultural na pós-modernidade. 7. ed. Rio de Janeiro, RJ: DP\&A, 2002. 102 p.

HERZHAFT, Gérard. Blues. Campinas, SP: Papirus, 1989. 138 p.

KARNAL, Leandro; PURDY, Sean; FERNANDES, Luiz Estevam; MORAIS, Macuw Vinícius. História dos Estados Unidos: das origens ao século XXI. 3. ed. São Paulo, SP: Contexto, 2011.

MUGGIATI, Roberto. Blues: da lama à fama. 3. ed. São Paulo, SP: Editora 34, 1995.

POSTALI, Thífani. Blues e hip hop: uma perspectiva folkcomunicacional. Jundiaí, SP: Paco Editorial, 2011.

PRODANOV, Cleber Cristiano; FREITAS, Ernani Cesar de. Metodologia do trabalho científico: métodos e técnicas da pesquisa e do trabalho acadêmico. 2. ed. Novo Hamburgo, RS: Feevale, 2013.

RIBEIRO, Filipa Perdigão Alexandre. A identidade afro-americana e a conquista da visibilidade. 2000. 329 f. Dissertação (Mestrado em Cultura NorteAmericana) - Departamento de Estudos Anglo-Portugueses, Faculdade de Ciências Sociais e Humanas, Universidade Nova de Lisboa, UNL, Lisboa, 2000.

ROBERTS, James Weldon Johnson. Autobiografia de um ex-negro. Porto Alegre, RS: BesouroBox, 2010. 
THE BLUES: warming by the devil's fire. Direção: Charles Burnett. Escritor: Charles Burnett. [S. I.]: PBS America, 2003. 7 vídeos. (1:28 min).

TOTA, Antônio Pedro. Os americanos. São Paulo, SP: Contexto, 2009.

TREPTOW, Doris. Inventando moda: planejamento de coleção. 5. ed. São Paulo, SP: Edição da Autora, 2013.

UDALE, Jenny. Fundamentos de design de moda: tecidos e moda. Porto Alegre, RS: Bookman, 2009. 